\title{
Spectrum of Neurological Disorders amongst Patients on Maintenance Haemodialysis in Douala, Cameroon: A Cross-Sectional Study
}

\author{
Halle Marie Patrice ${ }^{1,2}$, Tchouamou Tchouamou Eric Gildas ${ }^{1}$, Fouda Hermine ${ }^{2,3}$, \\ Gams Massi Daniel2,4, Ngamby Vincent Ebenezer ${ }^{1,5}$, Tewafeu Denis ${ }^{4,6}$, Kaze Folefack Francois ${ }^{3,7}$, \\ Mapoure Njankouo Yacouba1,2
}

\author{
${ }^{1}$ Faculty of Medicine and Pharmaceutical Sciences, University of Douala, Douala, Cameroon \\ ${ }^{2}$ Department of Internal Medicine, Douala General Hospital, Douala, Cameroon \\ ${ }^{3}$ Faculty of Medicine and Biomedical Sciences, University of Yaounde I, Yaounde, Cameroon \\ ${ }^{4}$ Faculty of Health Sciences, University of Buea, Buea, Cameroon \\ ${ }^{5}$ Department of Internal Medicine, Douala Laquintinie Hospital, Douala, Cameroon \\ ${ }^{6}$ Department of Internal Medicine, Regional Hospital of Buea, Buea, Cameroon \\ ${ }^{7}$ Yaounde Teaching Hospital, Yaounde, Cameroon \\ Email: ^patricehalle@yahoo.fr, etchouamo@ymail.com, mendjouf@yahoo.fr, dannygamsmassi@gmail.com, \\ vincentngamby@gmail.com, dengeorgt@gmail.com, fkaze@yahoo.fr, mapoureyacouba@gmail.com
}

How to cite this paper: Patrice, H.M., Gildas, T.T.E., Hermine, F., Daniel, G.M., Ebenezer, N.V., Denis, T., Francois, K.F. and Yacouba, M.N. (2022) Spectrum of Neurological Disorders amongst Patients on Maintenance Haemodialysis in Douala, Cameroon: A Cross-Sectional Study. Open Journal of Nephrology, 12, 112-123.

https://doi.org/10.4236/ojneph.2022.121011

Received: February 5, 2022

Accepted: March 6, 2022

Published: March 9, 2022

Copyright $\odot 2022$ by author(s) and Scientific Research Publishing Inc. This work is licensed under the Creative Commons Attribution International License (CC BY 4.0).

http://creativecommons.org/licenses/by/4.0/

\begin{abstract}
Context: Neurologic disorders are common in patients on maintenance haemodialysis (MHD). Data in Sub-Saharan Africa are scarce. Aim: To determine the prevalence and associated factors of neurological disorders amongst patients on MHD in Cameroon. Settings and Design: This was a four-month cross-sectional study carried out at the Douala General Hospital (DGH) a tertiary referral hospital in Cameroon. Methods: The diagnosis of neuropathy was made using the Michigan Neuropathy Screening Instrument (MNSI), neuropathic pain with the DN4 score, Restless Legs Syndrome (RLS) with the International Restless Legs Syndrome Study Group questionnaire (IRLSSG) and cognitive disorders with the Mini-Mental State Examination test (MMS). Student $\mathrm{T}$ and Chi-square tests were used to compare qualitative and quantitative variables. The level of significance was set at $\mathrm{p}<0.05$. Results: A total of 157 patients were included with $65 \%$ being males. The mean age was $48.8 \pm 13.7$ years. The main co-morbidities were hypertension $(90.4 \%)$, diabetes (19.1\%), hepatitis C (10.5\%) and HIV infection (10.8\%). The median dialysis vintage was $36(1-178)$ months. The overall prevalence of neurological disorders was $85.4 \%$. The leading type was sensory polyneuropathy
\end{abstract}


(57.3\%), cognitive dysfunction (52.9\%), neuropathic pain (23\%), and restless legs syndrome (17.8\%). Male gender was statistically associated with neuropathic pain, while age $\geq 40$ years and diabetes were associated with sensory neuropathy and RLS. Conclusions: The burden of neurological disorders is high among patients on MHD as up to $4 / 5$ of them had neurological involvement dominated by sensory polyneuropathy and cognitive dysfunction.

\section{Keywords}

Neurological Disorder, Haemodialysis, Prevalence, Cameroon

\section{Introduction}

Chronic kidney disease (CKD) is a worldwide public health problem with an $8 \%$ to $10 \%$ prevalence in the adult population [1]. Data in Africa are rare but the hospital-based prevalence in sub-Saharan Africa is estimated between $2 \%$ and $12 \%$ [2]. CKD accounted for 1\% - 5\% of global deaths in 2017 and was the 12 th leading cause of death globally [3]. CKD progress in five stages and at end-stage, renal replacement therapy (RRT) either dialysis or renal transplantation is necessary for survival [4].

Haemodialysis (HD) is the main modality of RRT [5] [6]. The outcome of patients on HD is characterized by a high morbidity and mortality rate [7] [8] [9] mainly due to comorbidities and HD complications [10]. These complications affect all body systems, especially the cardiovascular and nervous systems [11]. Neurological complications affect both the central nervous system such as stroke, cognitive dysfunction, and encephalopathy, and the peripheral nervous systems such as autonomic and peripheral neuropathies [12] [13]. These complications are mainly related to uremic toxins, dialysate type, water quality and HD follow-up [13]. They are found in almost $60 \%$ of patients with kidney failure (KF) patients [14]. These complications are generally underdiagnosed and consequently less treated, contributing to the morbidity and mortality of affected patients [12] [13]. In Cameroon, HD is the only RRT available and has been expanded considerably in the last decade with an increasing number of patients undergoing this treatment. The mortality rate is high and estimated at 26.8\% [15]. Data on neurological disorders amongst KF patients in Sub Sahara Africa are rare. This study aimed to determine the prevalence and factors associated with neurological disorders amongst patients on maintenance $\mathrm{HD}$ in a tertiary hospital in $\mathrm{Ca}$ meroon.

\section{Subjects and Methods}

\subsection{Study Setting and Participants}

This was a cross-sectional study carried out from January $1^{\text {str }}$ to $3^{\text {rd }}$ April 2018 in 
the haemodialysis and neurology units of the Douala General Hospital. At the time of the study, the center was equipped with 25 Fresenius $4008 S$ generators (Fresenius Medical Care, Hamburg, Germany), synthetic polysulfone dialysis membrane; and bicarbonate dialysate. The center had 2 nephrologists, 1 general practitioner, and 12 nursing staff, and opens from Monday to Saturday, runs 3 dialysis shifts a day and offers to registered patients two 4-hour dialysis sessions per week. All consenting patients with KF on maintenance haemodialysis (MHD) were included. For each patient, socio-demographic characteristics (age, gender, occupation, matrimonial status, residence, educational level, existence of health insurance), comorbidities such as diabetes, hypertension, HIV infection, hepatitis B and C, systemic diseases (lupus), gout, neurological pathologies (Stroke, Dementia). Presumed cause of KF, duration on dialysis, and current treatment were obtained from patient's files. Neurological disorders detected after dialysis initiation were also recorded.

A complete neurologic examination was done by a neurologist The Mini-Mental Status (MMS) was used to diagnose cognitive impairment [16] and for neuropathy the Michigan Neuropathy Screening Instrument (MNSI) was used [17], the International Restless Legs Syndrome Study Group questionnaire for the restless legs syndrome (IRLSSG) [18], and the DN4 score for neuropathic pain [19]. Tinel and Phalen's manoeuvres were used to diagnose carpal tunnel syndrome. Assessment of the autonomic nervous system was based on the patient's history and the Valsalva manoeuvre used to assess orthostatic hypotension. Co-morbidity evaluation was done using Charlson's score [20].

\subsection{Statistical Analysis}

Data were analyzed using the Statistical Package for Social Sciences (SPSS) Standard version, Release 20.0 (IBM Inc. 2012, Armonk, NY). Quantitative variables were expressed as means with standard deviation. The Student's T-test was used to compare means and the Chi-Square test to compare qualitative variables. Statistical significance was set at a $p<0.05$.

\subsection{Operational Definition of Terms}

- Neuropathic pain was defined by a DN4 score $\geq 4$.

- Orthostatic hypotension was defined, as a decrease of systolic blood pressure of more than $20 \mathrm{mmHg}$ and/or a decrease of diastolic blood pressure of more than $10 \mathrm{~mm} \mathrm{Hg}$ within 3 minutes of standing without modification of the heart rate.

- Carpal tunnel syndrome was considered in every patient with a positive Phalen and/or Tinel sign associated with acroparesthesia on the sensory distribution of the median nerve associated or not with atrophy of the thumb muscles.

- Restless legs syndrome was considered in every patient with an IRLSSG score > 4 for obligatory diagnostic criteria. 
- Neuropathy was considered in every patient with an MNSI Score $>3$ on clinical examinations and/or greater than 7 on the questionnaire.

- Cognitive impairment was considered in all patients with a mini-mental state examination (MMS) score less than that recommended for his/her level of education. The threshold values for normality were 19 for patients who benefited from 0 to 4 years of education, 23 for those with 5 to 8 years of education, 27 for patients with 9 to 12 years of education, 29 for patients who graduated from high school. Based on the score, cognitive impairment was classified as followed: absent if score between 29 to 26 , mild (25 to 20), moderate (19 to 16$)$ and dementia $(\leq 15)$.

\section{Results}

\subsection{Baseline Characteristics of the Study Population}

We included 157 patients with KF on MHD, of whom 107 (68.15\%) were males. The mean age was 48.8 (13.7) years. A total of 66/157 (42\%) patients were unemployed, and only $11 / 157$ (7\%) had a health insurance. Half (50.3\%) of the participants had a secondary level of education. Hypertension (142/157; 90.2\%) was the most frequent co-morbidity, followed by diabetes 30/157 (19.1\%) (Table 1). The main past neurological history was stroke (8.9\%) with $50 \%$ of cases occurring after dialysis initiation. The mean comorbidity score was $4.25 \pm 2.31$, with $26.1 \%$ of patients having scores ranging from high to very high. The median duration on dialysis was $36(1-178)$ months.

Table 1. Baseline characteristics of the study population.

\begin{tabular}{|c|c|c|}
\hline Variable & $\begin{array}{l}\text { Frequency } \mathrm{n} \\
\quad \mathrm{N}=157\end{array}$ & $\begin{array}{c}\text { Percentage (\%) } \\
100\end{array}$ \\
\hline Male & 107 & 68.15 \\
\hline Health insurance & 11 & 07 \\
\hline Unemployed & 66 & 42 \\
\hline Secondary level of education & 79 & 50.3 \\
\hline Hypertension & 142 & 90.4 \\
\hline Diabetes mellitus & 30 & 19.1 \\
\hline Hepatitis C & 17 & 10.8 \\
\hline HIV infection & 17 & 10.8 \\
\hline Gout & 15 & 9.6 \\
\hline Hepatitis B & 8 & 5.1 \\
\hline Past neurological illness & 18 & 11.5 \\
\hline Stroke & 14 & 8.9 \\
\hline Facial palsy & 1 & 0.6 \\
\hline Paraparesis & 1 & 0.6 \\
\hline Parkinsonian syndrome & 1 & 0.6 \\
\hline Meningioma & 1 & 0.6 \\
\hline
\end{tabular}




\subsection{Prevalence of Neurological Disorders and Associated Factors}

After clinical evaluation, tremors account was present in $24.8 \%$ of patients followed by myoclonus (9\%). Plastic hypertonia was present in $2.5 \%$ of patients and hyporeflexia/areflexia was the most reflex jerk abnormality encountered (48.4\%). Cranial nerve VIII was the main involved nerve (8.9\%) and orthostatic hypotension was found in $15.9 \%$ of case (Table 2).

Table 2. Neurological signs amongst study participants.

\begin{tabular}{lcc}
\hline \multicolumn{1}{c}{ Signs } & Frequency (n) & Percentage (\%) \\
\hline Motor signs & 14 & 9 \\
Myoclonus & 39 & 24.8 \\
Tremor & 7 & 4.5 \\
Asterixis & 3 & 1.9 \\
Fasciculations & 2 & 1.3 \\
\hline Muscle tone abnormalities & 4 & 2.5 \\
Spastic hypertonia & 2 & 1.3 \\
Plastic hypertonia & & \\
Hypotonia & 76 & 48.4 \\
\hline Reflex jerk of the lower limbs & 5 & 3.2 \\
Hyporeflexia/areflexia & &
\end{tabular}

\section{Sensitivity abnormality}

\section{Monofilament perception}

Reduced

46

44.58

Absent

16

11.94

Perception test on diapason

$\begin{array}{lcc}\text { Reduced } & 50 & 43.3 \\ \text { Absent } & 17 & 12.69\end{array}$

\section{Cranial nerve involvement}

$\begin{array}{lcc}\text { Nerve I } & 5 & 3.2 \\ \text { Nerve VII } & 6 & 3.8 \\ \text { Nerve VIII } & 14 & 8.9\end{array}$

\section{Orthostatic disturbances}

Orthostatic hypotension

25

Orthostatic vertigo

21

13.4

\section{Other syndromes}

Pyramidal syndrome

Cerebellar syndrome

Spinal cord compression

$10 \quad 6.4$

42.5

1
6.4

2.5

0.6 
Neurological disorders were found in $134 / 157$ patients (85.4\%), of which 64/157 (40.8\%) had mixed disorders involving the central and peripheral nervous systems. Reported symptoms were headache with 76/157 (48.9\%), sleep disorders with $69 / 157$ (45.1\%) and seizures 8/157 (5.1\%). The main central nervous disorders were cognitive impairment 83/157 (52.9\%) (Table 3) and it was mild in $42.2 \%$ of patients, moderate in $2.4 \%$ and dementia was present in $4.8 \%$ of patients. All patients with stroke were on dialysis for less than 6 months. The main peripheral nervous disorder was sensory polyneuropathy 90/157 (57.3\%) while neuropathic pain was found in 34/157 (21.7\%) patients and restless legs syndrome in $28(17.8 \%)$. Among the cases of sensory polyneuropathy, 26 were diabetic, 11 had hepatitis C and 9 patients were HIV positive. Diabetes mellitus was associated with the occurrence of sensory polyneuropathy and neuropathic pain $(\mathrm{p}<0.05)$, while age greater than 40 years was associated with both sensory polyneuropathy $(\mathrm{p}=0.001)$ and restless legs syndrome $(\mathrm{p}=0.02)$. Duration on $\mathrm{HD}$, presence of HIV, hepatitis B and C and gout were not associated to neurological disorders (Table 4).

\section{Discussion}

This study aimed to determine the prevalence of neurological disorders and their associated factors in patients on MHD. The prevalence of neurological manifestations was high (85.4\%). Cognitive impairment was the most common central nervous system manifestation while sensory polyneuropathy was the leading presentation of neuropathy. Male gender was associated with neuropathic pain while age $\geq 40$ years, diabetes was associated with sensory neuropathy and restless legs syndrome.

Few studies exist on the spectrum of neurological disorders in patients on MHD. Most of them assessed specific aspects. Rizzo et al. in a review estimate the prevalence of neurological disorders in these patients at $60 \%$ [14]. Our prevalence (85.4\%) was higher without the use of electrophysiology study (subclinical screening). An explanation could be the fact that patients in our setting received only 2 sessions of dialysis of 4 hours duration per week, instead of 3 sessions as

Table 3. Neurological disorders in the study population.

\begin{tabular}{ccc}
\hline Neurological disorders & Frequency (n) & Percentage (\%) \\
\hline Sensitive polyneuropathy & 90 & 57.3 \\
Cognitive dysfunction & 83 & 52.9 \\
Neuropathic pain & 34 & 21.7 \\
Restless legs syndrome & 28 & 17.8 \\
Orthostatic hypotension & 25 & 15.9 \\
Orthostatic Vertigo & 22 & 14.0 \\
Carpal Tunel syndrome & 14 & 8.9 \\
Stroke & 4 & 2.5
\end{tabular}


H. M. Patrice et al.

Table 4. Factors associated with neurological disorders among patients on MHD.

\begin{tabular}{|c|c|c|c|c|c|c|c|c|c|c|}
\hline Factors & CD n (\%) & $\mathrm{p}$ & PN n (\%) & $\mathrm{p}$ & NP n (\%) & $\mathrm{p}$ & $\mathrm{RLS}^{*} \mathrm{n}(\%$ & & OD n (\%) & $\mathrm{p}$ \\
\hline \multicolumn{11}{|l|}{ Sex } \\
\hline Female & $23(46.9)$ & & $22(68.8)$ & & $3(9.4)$ & & $9(28.1)$ & & $9(19.14)$ & \\
\hline Male & $60(57.1)$ & 0.27 & $68(84)$ & 0.07 & $33(40.7)$ & 0.001 & $15(18.5)$ & 0.26 & $16(16)$ & 0.56 \\
\hline \multicolumn{11}{|l|}{ Age (years) } \\
\hline$<40$ & $20(54.1)$ & & $9(47.4)$ & & 0 & & $8(42.1)$ & & $6(16.2)$ & \\
\hline $40-60$ & $34(44.2)$ & 0.32 & $45(83.3)$ & 0.003 & $14(25.9)$ & 0.99 & $11(20.4)$ & 0.07 & $14(18.7)$ & 0.75 \\
\hline$\geq 60$ & $29(72.5)$ & 0.09 & $38(90)$ & 0.001 & $22(55)$ & 0.99 & $5(12.5)$ & 0.02 & $5(13.9)$ & 0.78 \\
\hline \multicolumn{11}{|c|}{ Duration on HD } \\
\hline$<5$ years & $65(54.2)$ & & $70(83.3)$ & & $24(28.6)$ & & $18(21.4)$ & & $18(21.4)$ & \\
\hline$\geq 5$ years & $18(48.2)$ & 0.68 & $20(69)$ & 0.09 & $12(40)$ & 0.28 & $6(20)$ & 0.88 & $7(20)$ & 0.88 \\
\hline \multicolumn{11}{|l|}{ Hypertension } \\
\hline No & $7(46.7)$ & & $9(100)$ & & $3(100)$ & & $3(33.3)$ & & $4(33.33)$ & \\
\hline Yes & $76(54.7)$ & 0.55 & $81(77.9)$ & 0.20 & $33(77.9)$ & 0.91 & $21(20.2)$ & 0.40 & $21(20.2)$ & 0.40 \\
\hline \multicolumn{11}{|l|}{ Diabetes } \\
\hline Non & $66(52.8)$ & & $64(73.3)$ & & $23(26.4)$ & & $20(23)$ & & $20(23)$ & \\
\hline Oui & $17(58.6)$ & 0.57 & $26(100)$ & 0.003 & $13(50)$ & 0.02 & $4(15.4)$ & 0.41 & $5(15.4)$ & 0.41 \\
\hline \multicolumn{11}{|l|}{ Hepatitis B } \\
\hline No & $78(53.1)$ & & $85(80.2)$ & & $34(80.2)$ & & $22(20.8)$ & & $22(20.8)$ & \\
\hline Yes & $5(71.4)$ & 0.45 & $5(71.4)$ & 0.71 & $2(71.4)$ & 0.85 & $2(28.6)$ & 0.64 & $3(28.6)$ & 0.64 \\
\hline \multicolumn{11}{|l|}{ Hepatitis C } \\
\hline No & $74(53.6)$ & & $79(79.8)$ & & $28(28.3)$ & & $20(20.2)$ & & $20(20.2)$ & \\
\hline Yes & $9(56.9)$ & 0.84 & $11(78.6)$ & 1.00 & $8(57.1)$ & 0.06 & $4(15.4)$ & 0.49 & $5(28.6)$ & 0.72 \\
\hline \multicolumn{11}{|l|}{ HIV } \\
\hline No & $74(69.8)$ & & $81(80.2)$ & & $35(34.7)$ & & $21(20.8)$ & & $21(20.8)$ & \\
\hline Yes & $9(52.4)$ & 0.41 & $9(75.0)$ & 0.71 & $1(8.3)$ & 0.10 & $3(25)$ & 0.72 & $4(25)$ & $0 . .72$ \\
\hline \multicolumn{11}{|l|}{ Gout } \\
\hline No & 74 (52.9) & & $60(82.2)$ & & $29(52.9)$ & & $21(21.2)$ & & $21(21.2)$ & \\
\hline Yes & $9(64.3)$ & 0.41 & $20(75.0)$ & 0.36 & $9(64.3)$ & 0.14 & $3(11.4)$ & 1.00 & $4(11.4)$ & 1.00 \\
\hline
\end{tabular}

CD: Cognitive Dysfunction; PN: Polyneuropathy; NP: Neuropathic Pain; OD: Orthostatic dysfunction; HIV: Human Immunodeficiency Virus; RLS: Restless Legs Syndrome; HD: Hemodialysis.

recommended and also the shortage of dialysis consumables that lead to irregular dialysis sessions. These are factors that contribute to poor dialysis and the accumulation of uremic toxins that are known to be toxic for nerves.

Sensory polyneuropathy was the most present disorder (17.3\%) using the MNSI which is a validated score for the diagnosis of peripheral neuropathy [17]. Among these patients, more than half (51\%) had other diseases susceptible to induce polyneuropathy such as diabetes, HIV, hepatitis B and C. Mambelli et al. in Italy, and Tiki et al. in Turkish reported respectively a prevalence of $61.3 \%$ and $97 \%$ for polyneuropathy amongst patients on MHD [18] [19]. These high prevalence in their studies could be due to the fact that they used electromyoneurography, which enables infra clinical diagnosis of neuropathies, and also the rate of patients with risk factors (comorbidities) of neuropathy in their studies 
was higher.

A decrease in the amplitude of sensory potential was remarkable on the median, ulnar and sural nerves. Whereas the motor conduction velocity was reduced on the peroneal nerve associated to an increased latence interval. As for non-uremic polyneuropathies, excluding diabetes and viral infections that are common in Cameroon [21] [22] [23], another study reported in 20 patients on MHD with neuropathy, four cases of non uremic neuropathy notably one Guillain Barre syndrome, one chronic polyradiculoneuritis, one progressive spinal amyothrophy and a case associated to transplantation [24]. These findings suggest the multifactorial origin of polyneuropathy in our context.

Similar to Mambelli et al., increased age was associated to polyneuropathy as well as type 2 diabetes [18], which generally occurs with age justifying their coexistence as associated factors in our study. Cognitive impairment was present in $52.9 \%$ of which $4.8 \%$ of cases were recognized dementia. Our results were similar to those of Pereira et al. in Brazil who reported $40 \%$ of case [25]. These increased proportions can be explained by the presence of several major cerebrovascular risk factors such as hypertension, diabetes and HIV; and also, by the episodes of cerebral hypo perfusion occurring during dialysis sessions resulting in transient ischemia enhancing nerve cell damage in these patients. In 2012, Kurella et al. in the USA [26], in a series of 80 patients found that $38 \%$ of patients had severe dementia. This proportion is far greater than the $4.8 \%$ in our study. The mean age of their patients estimated at 61 years (versus 48 years in our study), could have contributed to an increase in the proportion of dementia.

Headache was the main symptom with a prevalence of $48 \%$ compared to $44 \%$ found by Aladlouni et al. in Morocco [27] and 40\% reported by Goksan et al. in Turkey [28]. In Brazil, Antoniazzi et al. then Feitosa et al. respectively had 70 and $76 \%$ cases of headache [29] [30]. The main clinical presentations were migraine (48\%), tension-type headache (19\%) and associated forms (migraine and tension-type headache) in $8 \%$ of patients [28]. Sleep disorders were found in $44.4 \%$ of patients. These results are similar to the prevalence $(44 \%)$ of sleep disorders reported in the study Giovanni et al. [31] but about much lower than those reported by Sabry et al. in Egypt (79.5\%) and Merlino et al. in Italy (80\%) [32] [33]. This difference could be linked to the study method used; in our study, the diagnosis was mainly clinical in contrast with these two studies that used well defined scores in addition to polysomnography.

In our study, the prevalence of restless legs syndrome was $17.8 \%$ using IRLSSG criteria. This result is in the range with those of Araujo et al. (21.5\%) on a population of 400 patients and Salman et al. in Saudi Arabia (20.3\%) on 123 patients using the same questionnaire [34] [35]. Age greater than 60 years was associated with restless legs syndrome, similar to the report of Araujo et al. [34]. This association could be justified by the fact that increased age enhances the degenerescence of descending dopaminergic pathways which could cause restless legs syndrome [35]. Finally, no association was found between restless legs syndrome and comorbidities, nor duration of dialysis, similar to other studies in the litera- 
ture [34] [35].

Autonomic dysfunctions were frequent in chronic haemodialysis patients. Orthostatic hypotension was found in $15.9 \%$. In our study, diabetes was the second comorbidity (19.1\%) inducing severe neuropathies with autonomic dysfunction responsible for orthostatic hypotension. Sasaki et al. in Japan reported a prevalence three times ours (42\%) [36]. The mean duration of dialysis in this Japanese study could explain the difference (14 years against 3 years in our study). The mechanism remains yet unknown.

Carpal tunnel syndrome was found in $8.9 \%$ of our patients who had a common characteristic of dialysis duration greater than 5 years. In fact, carpal tunnel syndrome is due to the accumulation of Beta-2 microglobulin, in particular and juxta-articular structures. Whereas Beta-2-microglobulin is a uremic toxin mildly eliminated via $\mathrm{HD}$ hence the correlation with the duration of dialysis. Using clinical criteria, our result is closed to that reported by Kopec et al. and Mbarki et al. in Tunisia which found respectively $10.4 \%$ and $8.3 \%$ [37] [38]. However, our finding was low compared to that of Namazi et al. (30.5\%) [39]. This could be due to the fact that in their study, an electromyoneurography was performed and the duration on dialysis was much longer (10 years) [39].

This study has shortcomings which include mainly the absence of electrophysiological assessment for diagnostic confirmation and better appreciation of subclinical involvement. But the nature of this study, using validated tools for diagnosis purposes gives an idea of preliminary data and should serve as a baseline for further studies to improve the management of these disorders and comorbidities.

\section{Conclusion}

The prevalence of neurological disorders was high among patients on MHD in the DGH affecting up to $4 / 5$ of them. Neurological involvement was numerous and dominated by sensory polyneuropathy and cognitive dysfunction. There is a need to put in place measures to manage these complications and improve the quality of life of affected patients.

\section{Declarations}

\section{Ethical Considerations and Consent to Participate}

Ethical approval was obtained from the institutional review board of the University of Douala, Cameroon. All participants and/or their relatives provided written consent. Patients with neurological disorders were addressed to the neurology unit for further management.

\section{Authors' Contribution}

HMP, MNY, TTEG: Study conception and design;

TTEG, FH, GM, NV: data collection and supervision;

TTEG, GM, KFF, TD, HMP: data and analysis and interpretation;

HMP, MNY: drafting of the manuscript; 
TTEG, NV, TD, KFF: critical revision of the manuscript;

All authors read and approved the final manuscript.

\section{Acknowledgements}

We are grateful all the patients who agreed to participate in this study

\section{Conflicts of Interest}

The authors declare that they have no competing interests

\section{References}

[1] Hill, N.R., Fatoba, S.T., Oke, J.L., Hirst, J.A., O’Callaghan, C.A., Lasserson, D.S. and Hobbs, F.D. (2016) Global Prevalence of Chronic Kidney Disease-A Systematic Review and Meta-Analysis. PLoS ONE, 11, e0158765.

https://doi.org/10.1371/journal.pone.0158765

[2] Kaze, F.F., Ashuntantang, G., Kengne, A.P., Hassan, A., Halle, M.P. and Muna, W. (2012) Acute Hemodialysis Complications in End-Stage Renal Disease Patients: The Burden and Implications for the Under-Resourced Sub-Saharan African Health Systems. Hemodialysis International, 16, 526-531. https://doi.org/10.1111/j.1542-4758.2012.00692.x

[3] GBD Chronic Kidney Disease Collaboration (2020) Global, Regional, and National Burden of Chronic Kidney Disease, 1990-2017: A Systematic Analysis for the Global Burden of Disease Study 2017. The Lancet, 395, 709-733.

[4] Fraser, S.D. and Blakeman, T. (2016) Chronic Kidney Disease: Identification and Management in Primary Care. Pragmatic and Observational Research, 7, 21-32. https://doi.org/10.2147/POR.S97310

[5] Cavanaugh, K.L., Merkin, S.S., Plantinga, L.C., et al. (2008) Accuracy of Patients' Reports of Comorbid Disease and Their Association with Mortality in End-Stage Renal Disease. American Journal of Kidney Diseases, 52, 118-127. https://doi.org/10.1053/j.ajkd.2008.02.001

[6] Grassman, A., Gioberge, S., Moeller, S. and Brown, G. (2005) ESRD Patient in 2004: Global Overview of Patient Numbers, Treatment Modalities and Associated Trends. Nephrology Dialysis Transplantation, 20, 2587-2593. https://doi.org/10.1093/ndt/gfi159

[7] Goodkin, D.A., Bragg-Gresham, J.L., Koenig, K.G., Wolfe, R.A., Akiba, T. and Andreucci, V.E. (2003) Association of Comorbid Conditions and Mortality in Hemodialysis Patients in Europe, Japan, and the United States: The Dialysis Outcomes and Practice Patterns Study (DOPPS). Journal of the American Society of Nephrology, 14, 3270-3277. https://doi.org/10.1097/01.ASN.0000100127.54107.57

[8] Naicker, S. (2003) End-Stage Renal Disease in Sub-Saharan and South Africa. Kidney International Supplements, 83, 119-122.

[9] Shibiru, T., Gudina, E.K., Habte, B., Derbew, A. and Agonafer, T. (2013) Survival Patterns of Patients on Maintenance Hemodialysis for End Stage Renal Disease in Ethiopia: Summary of 91 Cases. BMC Nephrology, 14, Article No. 127. https://doi.org/10.1186/1471-2369-14-127

[10] United States Department of Health and Human Services, Public Health Service, National Institutes of Health, National Institute of Diabetes and Digestive and Kidney Diseases, U.S. Renal Data System (USRDS) (2012) USRDS 2012 Annual Data 
Report: Atlas of Chronic Kidney Disease and End-Stage Renal Disease in the United States. USRDS, Bethesda, MD.

[11] Menanga, A., Ashuntantang, G., Kollo, D., Hamadou, B., Kaze, F., Wawo, E., et al. (2013) Hyperkalaemia in Chronic Hemodialysis Patients at Yaoundé: Prevalence, Clinical and Electrocardiographic Manifestations. Health Sciences and Diseases, 14, No. 4.

[12] Brouns, R. and De Deyn, P.P. (2004) Neurologic Complications in Renal Failure: A Review. Clinical Neurology and Neurosurgery, 107, 1-16. https://doi.org/10.1016/j.clineuro.2004.07.012

[13] Krishnan, A.V. and Kiernan, M.C. (2009) Neurological Complications of Chronic Kidney Disease. Nature Reviews Neurology, 5, 542-551.

https://doi.org/10.1038/nrneurol.2009.138

[14] Rizzo, A., Frediani, F., Granata, A., Ravasi, B., Cusi, D. and Gallieni, M. (2012) Neurological Complications of Hemodialysis: State of the Art. Journal of Nephrology, 25, 170-182.

[15] Halle, M.P., Ashuntantang, G., Kaze, F.F., Takongue, C. and Kengne, A.P. (2016) Fatal Outcomes among Patients on Maintenance Haemodialysis in Sub-Saharan Africa: A 10-Year Audit from the Douala General Hospital in Cameroon. BMC Nephrology, 17, Article No. 165. https://doi.org/10.1186/s12882-016-0377-5

[16] Folstein, M.F., Folstein, S.E. and McHugh, P.R. (1975) “Mini-Mental State” A Practical Method for Grading the Cognitive State of Patients for the Clinician. Journal of Psychiatric Research, 12, 189-198. https://doi.org/10.1016/0022-3956(75)90026-6

[17] Moghtaderi, A., Bakhshipour, A. and Rashidi, H. (2006) Validation of Michigan Neuropathy Screening Instrument for Diabetic Peripheral Neuropathy. Clinical Neurology and Neurosurgery, 108, 477-481. https://doi.org/10.1016/j.clineuro.2005.08.003

[18] Mambelli, E., Barrella, M. and Facchini, M. (2012) The Prevalence of Peripheral Neuropathy in Hemodialysis Patients. Clinical Nephrology, 77, 468-475.

https://doi.org/10.5414/CN107188

[19] Tilki, H.E., Alpolat, T., Coskum, S.E. and Stålberg, E. (2009) Clinical and Electrophysiologic Findings in Dialysis Patients. Journal of Electromyography and Kinesiology, 19, 500-508. https://doi.org/10.1016/j.jelekin.2007.10.011

[20] Charlson, M.E., Pompei, P., Ales, K.L. and Mackenzie, C.R. (1987) A New Method of Classifying Prognostic Comorbidity in Longitudinal Studies: Development and Validation. Journal of Chronic Diseases, 40, 373-383. https://doi.org/10.1016/0021-9681(87)90171-8

[21] UNAIDS (2013) UNAIDS Report Global AIDS Epidemic 2013.

[22] Mora, N., Adams, W.H., Kliethermes, S., Dugas, L., Balasubramanian, N., Sandhu, T., et al. (2016) A Synthesis of Hepatitis C Prevalence Estimates in Sub-Saharan Africa: 2000-2013. BMC Infectious Diseases, 16, Article No. 283. https://doi.org/10.1186/s12879-016-1584-1

[23] Bigna, J.J., Amougou, M.A., Asangbeh, S.L., et al. (2017) Seroprevalence of Hepatitis B Virus Infection in Cameroon: A Systematic Review and Meta-Analysis. BMJ Open, 7, e015298. https://doi.org/10.1136/bmjopen-2016-015298

[24] Kondo, H., Takenchl, M., Yatabe, K., Mochtzuki, A. and Imata, M. (1997) Non Uremic Neuropathy in Hemodialysed Patient. No to Shinkei, 49, 737-743.

[25] Pereira, A.A., Weiner, D.E. and Scott, T. (2005) Cognitive Function in Dialysis Patients. American Journal of Kidney Diseases, 45, 448-462.

https://doi.org/10.1053/j.ajkd.2004.10.024 
[26] Kurella, M., Chertow, G.M., Fried, L.F., Cummings, S.R., Harris, T., Simonsick, E., et al. (2005) Chronic Kidney Disease and Cognitive Impairment in the Elderly: The Health, Aging, and Body Composition Study. Journal of the American Society of Nephrology, 16, 2127-2133. https://doi.org/10.1681/ASN.2005010005

[27] Aladlouni, A., Knidiri, H., Fadili, W., Laouad, I., El Bakaye, M. and Kissani, N. (2012) Évaluation des troubles neurologiques chez les patients hémodialysés chroniques. Néphrologie \& Thérapeutique, 8, 327. https://doi.org/10.1016/j.nephro.2012.07.262

[28] Göksan, B., Karaali-Savrun, F., Ertan, S. and Savrun, M. (2004) HaemodialysisRelated Headache. Cephalalgia, 24, 284-287. https://doi.org/10.1111/j.1468-2982.2004.00668.x

[29] Antoniazzi, A., Marcelo, E., Bigal, M., et al. (2003) Headache and Hemodialysis: A Prospective Study. Headache, 43, 99-102. https://doi.org/10.1046/j.1526-4610.2003.03025.x

[30] Feitosa de Jesus, A., Araújo, O. and Ribeiro, O.M. (2009) Clinical Description of Hemodialysis Headache in End-Stage Renal Disease Patients. Arquivos de NeuroPsiquiatria, 67, 978-981. https://doi.org/10.1590/S0004-282X2009000600003

[31] Merlino, G., Pian, A. and Dolso, P. (2008) Sleep Disorders in Patients with EndStage Renal Disease Undergoing Dialysis Therapy. Journal of Nephrology, 21, 66-70.

[32] Sabry, A.A., Abo-Zenah, H. and Wafa, E. (2010) Sleep Disorders in Hemodialysis Patients. Saudi Journal of Kidney Diseases and Transplantation, 21, 300-305.

[33] Merlino, G., Piani, A., Dolso, P., et al. (2006) Sleep Disorders in Patients with EndStage Renal Disease Undergoing Dialysis Therapy. Nephrology Dialysis Transplantation, 21, 184-190. https://doi.org/10.1093/ndt/gfil44

[34] Araujo, S.M., de Bruin, V.M., Nepomuceno, L.A., Maximo, M.L., Daher Ede, F., Correa Ferrer, D.P., et al. (2010) Restless Legs Syndrome in End-Stage Renal Disease: Clinical Characteristics and Associated Comorbities. Sleep Medicine, 11, 785 790. https://doi.org/10.1016/j.sleep.2010.02.011

[35] Salman, S.M., et al. (2011) Restless Legs Syndrome in Patients on Hemodialysis. Saudi Journal of Kidney Diseases and Transplantation, 22, 368-372.

[36] Sasaki, O., Nakaham, H. and Nakamura, S. (2005) Orthostatic Hypotension at the Introductory Phase of Haemodialysis Predicts All-Cause Mortality. Nephrology Dialysis Transplantation, 20, 377-381. https://doi.org/10.1093/ndt/gfh614

[37] Kopeć, J., Gadek, A., Drozdz, M., et al. (2011) Carpal Tunnel Syndrome in Hemodialysis Patients as a Dialysis-Related Amyloidosis Manifestation-Incidence, Risk Factors and Results of Surgical Treatment. Medical Science Monitor, 17, CR505CR509.

[38] Mbarki, H., Amine, A. and Lazrak, A. (2013) Le syndrome du canal carpien chez les patients hémodialysés chroniques. The Pan African Medical Journal, 14, Article No. 19.

[39] Namazi, H. and Majd, Z. (2007) Carpal Tunnel Syndrome in Patients Who Are Receiving Long-Term Renal Hemodialysis. Archives of Orthopaedic and Trauma Surgery, 127, 725-728. https://doi.org/10.1007/s00402-007-0350-7 